\title{
Peer Support Groups: Evaluating a Culturally Grounded, Strengths-Based Approach for Work With Refugees
}

\author{
Azadeh Masalehdan Block \\ Leslie Aizenman \\ Adam Saad \\ Stephanie Harrison \\ Amanda Sloan \\ Simone Vecchio \\ Vanessa Wilson
}

\begin{abstract}
Many refugees will face unique socio-emotional stressors before, during, and after resettling in their new home country. The program presented herein focuses on the use of para-professionals, peer educators, from within refugee communities to build upon the Center for Torture and Trauma Survivors Clubhouse model. Group leaders seek to provide supports that will: 1) decrease feelings of isolation; 2) build community networks and; 3) increase feelings of empowerment within the community. To accurately represent the fluidity of the refugee population in this metropolitan region, background is presented on an established refugee population from Iraq and a more recent influx of refugees of Bhutan (ethnic Nepali). The juxtaposition of the two groups underscores the importance of presenting a dynamic program that is peer-led to provide the supports necessary to acclimate to their new environment. Program evaluation results from groups run in 20162017 indicate that the groups have been successful in helping participants make friends, get information, become more independent, and feel better about life in America. Additionally, participants report a significantly higher number of individuals who they can "talk to about problems or worries" and connect to with a sense of trust within their ethnic community. Finally, the utility of other therapeutic and support processes, such as horticultural and expressive arts therapies, are discussed apropos work with refugee populations.
\end{abstract}

Keywords: Refugee; peer support; social work; community; group work

\section{Background and Significance}

According to the United Nations High Commissioner for Refugees (2010), a refugee is someone who "owing to a well-founded fear of being persecuted for reasons of race, religion, nationality, membership of a particular social group or political opinion, is outside the country of his nationality, and is unable to, or owing to such fear, is unwilling to avail himself of the protection of that country" (p. 3). Refugees come from a variety of locations around the world, and each refugee carries with them a unique set of values, cultural

Azadeh Masalehdan Block, MSW, PhD is an Assistant Professor, Department of Social Work, California University of PA, California, PA. Leslie Aizenman, MPPM is Director of Refugee Services at Jewish Family and Community Services of Pittsburgh, PA. Stephanie Harrison, MA and Adam Saad, MA are affiliated with Chatham University, Pittsburgh, PA. Amanda Sloan is a student at the School of Social Work, University of Pittsburgh, Pittsburgh, PA. Simone Vecchio, MID is a project manager at Jewish Family and Community Services of Pittsburgh, PA. Vanessa Wilson, MS, is a statistician at the Oregon Health Authority, Salem, OR. 
identity, and language. Refugees do not choose to relocate themselves but are instead compelled to leave their countries in order to protect their lives and/or their freedom.

Refugees are subject to a variety of stressors both before and after their resettlement. The events leading up to their displacement can be wrought with political violence, war, or related threats (Cole \& Blythe, 2010). Many refugees will have been subject to some form of trauma either directly or indirectly. Refugees from collectivistic cultures will often share traumas of oppression, discrimination, and torture through a collective identity (Karcher, Kuperminc, Portwood, Sipe, \& Taylor, 2006). However, individuals of a certain nationality may experience persecution or trauma because of their belonging to a certain subgroup. This is prevalent in cases of ethnic and religious persecution.

It is common for researchers and practitioners to focus on the trauma that refugees have endured; therefore, the majority of treatment programs for refugees focus on symptoms of Post-Traumatic Stress Disorder (PTSD, Obradovic, Tirado-Strayer, \& Leu, 2013; Watters, 2001). Symptoms of PTSD can include difficulty sleeping, bad dreams, and loss of interest in activities. This can be a major concern for health care providers of refugees as PTSD can be difficult to treat in cultures where psychotherapy is not widely accepted.

Nevertheless, it is important not to label all refugees as suffering from some type of pathology because they are all individuals going through extraordinary circumstances. Health care professionals should be conscious of cultural differences that may arise when interacting with refugees, and to seek strengths-based approaches for work with clients (Congress \& Chang-Muy, 2015). Various cultures have differing concepts on time management, family dynamics, and social interactions. Often the circumstances that refugees experience upon resettlement may also be complex and can include poor school systems, poverty, unsafe neighborhoods, and bullying (Cole \& Blythe, 2010; MENTOR, 2009; Schweitzer, Brough, Vromans, \& Asic-Kobe, 2011). Social workers and others working with refugees must consider and acknowledge cultural differences on the pathway to acculturation/assimilation.

After resettlement, a variety of factors can affect refugees: feelings of isolation, depression, and somatization. Research that studied the mental health of refugees and their resettlement found an association between post-displacement conditions and mental health outcomes (Kaslow, 2014; Porter \& Haslam, 2005). Therefore, psychopathology among refugees is not necessarily a consequence of posttraumatic wartime stressors but can reflect contextual factors about the displacement process (Kim, 2013). In order to provide adequate care to refugees, it is necessary to realize that the stressors that are a part of their resettlement can have significant impacts on their mental health (Shannon, Vinson, Wieling, Cook, \& Letts, 2015). The psychological consequences of displacement cannot simply be labeled the product of acute stressors of trauma but should instead be understood in the context of the economic, social, and cultural conditions from where the refugees are displaced and those in which they are resettled (Shannon, Wieling, Simmelink-McCleary, \& Becher, 2015).

This paper presents the results of a program evaluation designed to obtain information about social services desired and utilized in an urban/suburban population of immigrants and refugees engaged in a peer-support group. Agency administrators at a Pittsburgh based 
Jewish Family and Community Services (JFCS) chose a strengths-based peer support model for myriad reasons, including, but not limited to: cultural sensitivity, costeffectiveness and face validity in promoting social integration. Program goals included: 1 . Decrease feelings of isolation, 2. Build community networks, and 3. Increase feelings of empowerment within the community.

\section{Literature Review}

\section{Group Work with Refugees}

JFCS assists refugees in several ways: gaining access to welfare, English as a Second Language Programs (ESL), accessing health services, and assistance in green card applications. Additionally, JFCS provides acculturation workshops to refugees with information about topics such as safety, hygiene, healthcare, U.S. laws, public benefits, employment, banking and budgeting, etc. As it applies to health, these workshops also stress the importance of preventative care as opposed to reactionary health care. However, the needs of the refugee populations extend beyond the confines of an acculturation workshop. Connecting clients with support networks is a critical tool in the broader issue of addressing social and mental health.

A strengths-based group therapy approach to working with refugees addresses the need for community healing of the refugee population (Drozdek \& Bolwerk, 2010; Im \& Rosenberg, 2016; Kira, Ahmed, Mahmoud, \& Wassim, 2010). This strengths-based approach is culturally appropriate, flexible, and tailored to the unique needs of this population. Many clients of JFCS belong to collectivistic cultures in which healing takes place within the community. Individual psychotherapy is often steeped with individualism and western ideals, which may not coincide with the refugees' cultural values. Additionally, because refugees often experience cumulative trauma, challenges to personal identity as well as community and social identity occur. In order for community and social identity to be repaired, a group therapy approach targeting collective self-esteem and rebuilding group identity are essential (Drozdek \& Bolwerk, 2010; Kira et al., 2011). Research with this population suggests more positive outcomes for refugees receiving group therapy compared to those receiving individual therapy (Bass et al., 2013).

Peer models have been used successfully in immigrant/refugee acculturation programs throughout the world including peer education programs for communicable illnesses (Broadhead et al., 2002; Thomas, Clarke, \& Kroliczak, 2008); whereas support groups have been efficacious in treating numerous populations ranging from addiction to new parent support groups (Yalom, 2005). Research suggests that after social support interventions, refugees reported increased social integration, decreased loneliness, and healthier coping skills (Stewart, Simich, Shizha, Makumbe, \& Makwarimba, 2012). A strengths-based support group model embraces concepts like cultural humility and competence as it is rooted in community growth and strength. Researchers have suggested that having others from their homeland as a part of the group welcoming and acclimating them to their new surroundings helps in easing into the transition to a new location (Kaslow, 2014). Therefore, a peer-administered social support group is an excellent fit for the growing refugee communities in Allegheny County as it is grounded in the communities' natural 
support system, is a strengths-based approach, and is sustainable as peers learn the tools to empower and continually learn from and support one another.

Additionally, because refugees are less likely to use traditional mental health services, the strengths-based peer support model provides a much-needed outlet for social and emotional healing (Cole \& Blythe, 2010). In fact, the use of peer models may have a positive impact on stigma in using mental health services aiming to potentially empower the community in addressing mental health issues from within (Thomas et al., 2008). Evidence suggests that refugees are likely to seek out services based on meeting their hierarchical needs (food and shelter before education) (Geltman, Augustyn, Barnett, Klass, \& Groves, 2000). This approach is also economically practical as it has the ability to address the needs of several individuals concurrently, and the cost of staffing is less than that of a traditional mental health group.

\section{Peer Support Models with Refugees}

Peer-led interventions start from a point of commonality. In the realm of health outcomes, have been proven to increase positive outcomes in members of their community (Im \& Rosenberg, 2016; Webel, Okonsky, Trompeta, \& Holzemer, 2010). Extensive research has been done using the Promotores model and it is well-documented that this peer health education model is beneficial to client health outcomes. A recent meta-analysis found that peer groups are especially effective with hard-to-reach and cultural minority populations--further evidence that the peer model is the right fit for the populations and communities in the Pittsburgh region (Webel et al., 2010).

In researching best practices for strengths-based support group work with the refugee population, several "best practice" guidelines were identified. These included: a community-based model focused on present stress first and past trauma second, homogeneity of members, flexible but structured sessions, and community network building (Kira et al., 2011). JFCS has adapted the Center for Torture and Trauma Survivors' (CTTS) clubhouse model for use with the refugee and recent population in Allegheny County. The CTTS clubhouse model follows each "best practice guideline" and was adapted to fit the needs of refugees from numerous cultural backgrounds. It is critical that evidence-based practice (EBP) be the centerpiece of the work with these populations. EBPs include a grounding in empirical evidence coupled with integration of the latest research evidence: a critical combination for effective treatment with clients who may have additionally experienced trauma (Strand, Popescu, Way, \& Jones, 2017). The clubhouse model is a culturally sensitive, adaptable, and sustainable model that provides evidence for therapeutic efficacy. Several organizations around the globe have adopted similar support group models including: Freedom from Torture based in the U.K, the Bellevue/NYU program developed by Dr. Hawthorne Smith, the Advocates for Survivors of Torture and Trauma model based in Baltimore, and Nah We Yon, an African women's refugee support group based in New York City. All of these organizations have documented the economic and therapeutic sustainability of their adaptations of this model. 


\section{JFCS Peer Support Program}

JFCS has adapted the CTTS clubhouse model for use in an eight-week open format support group (sometimes separated by gender depending on the ethnicity). The group follows an open format in that men or women are invited to participate and drop-in attendance is permitted. The concept behind the drop-in attendance is to allow the communities to view the group as being open, and in tune with cultural mores, where attendance does not prevent an individual from participation.

Peer facilitators receive training at JFCS in group dynamics, cultural sensitivity, and recognizing and referring individuals: 1) in need of mental health services, or 2) at risk of harm to self or others, to the appropriate resources. Peer facilitators are encouraged to check in with group members via telephone or email in order to facilitate communication and develop stronger bonds and to acknowledge that pressing questions or concerns cannot always wait until the next meeting (Fischhoff, 1986). Allowing group members to check in with the facilitators or other group members in between sessions serves to strengthen the group's sense of community and build upon community ties that are being built during group sessions. Pre/post group assessments are conducted in the first session (in person) and after the final session (via phone using an interpreter) in order to obtain data on the progress of the group.

Following best practice guidelines, the CTTS clubhouse model combines a variety of therapies into one cohesive strengths-based support group environment. CTTS developed groups for Iraqi men, women, and families, Burmese men, Bhutanese (ethnic Nepali) families, and pan-African women who have survived torture, trauma, and oppression (Kira et al., 2011). Session content includes: emotional exploration, education on topics ranging from building a resume to symptoms of PTSD, traditional healing methods such as dance and movement therapy, art and music therapy, as well as meditation, storytelling, cooking and eating, and bead working have been used depending on the preference of the group.

The emotional exploration provides community building, normalization, support, and acceptance, which can lead to decreased feelings of isolation, depressive symptoms, anxiety, and PTSD symptoms (Kira et al., 2011). Exploration of current life stressors, acculturation issues, religious, and political issues are common. The education involved in the session largely depends on the needs and desires of the clients. Members suggest topics for discussion allowing the concrete, present needs of the individuals to be met. This also allows the clients to feel empowered and strengthened by decision-making and knowledge. Members are able to brainstorm, use problem-solving skills, and learn from one another thus producing community network building, community self-esteem, and a sense of support (Lubin, Loris, Burt, \& Johnson, 1998).

JFCS was not able to obtain any formal training curriculum from CTTS. A manual was created based on evidence-based practice with peer-led groups for refugee populations completed by CTTS and described by Kira et al. (2010) and Kira et al. (2011). The manual includes two sections, Part 1: basic instruction and information on group dynamics, group participation styles and how to manage groups effectively; and Part 2, which offers a curriculum that can be tailored to meet the needs of each unique population and provide 
the resources needed. The ten different content areas to be covered over the eight weeks (i.e. some weeks may include more than one content area), See Table 1.

\section{Table 1. CTTS Weekly Content Areas}

\begin{tabular}{ll}
\hline Section(s) & Content Area \\
\hline 1 & $\begin{array}{l}\text { An introduction and overview of group structure and foreshadowing for more } \\
\text { distinct content }\end{array}$ \\
\hline 2 & $\begin{array}{l}\text { Life in a different culture: which focuses on issues of acculturation } \\
\text { Taking care of yourself: which focuses on tools for self-care and stress } \\
\text { management }\end{array}$ \\
\hline 5 & $\begin{array}{l}\text { Health care in the United States: which provides group members information on } \\
\text { how to seek health care in the United States }\end{array}$ \\
\hline 6 & $\begin{array}{l}\text { Building a strong support system: which provides instruction on identifying } \\
\text { friends, family members and other resources who they can turn to for support } \\
\text { and help }\end{array}$ \\
\hline 7 & $\begin{array}{l}\text { Family life in the United States: which helps group members identify the } \\
\text { differences between family life in their native countries and give group members } \\
\text { an opportunity to discuss challenges they've faced in adapting to family life in } \\
\text { the United States }\end{array}$ \\
\hline 8 & $\begin{array}{l}\text { Employment: which helps participants to recognize and promote their personal } \\
\text { strengths to improve chances of employment }\end{array}$ \\
\hline 9 & $\begin{array}{l}\text { Legal immigration and naturalization issues: which provides group members } \\
\text { with needed information on legal issues regarding immigration and } \\
\text { naturalization }\end{array}$ \\
\hline $\begin{array}{l}\text { Final session: which provides for debriefing, identifying next steps and } \\
\text { connecting group members to new resources as necessary }\end{array}$ \\
\hline 10 &
\end{tabular}

Homogenous groups are generally preferred when working with refugees (Fischman \& Ross, 1990). The CTTS clubhouse model also stresses the importance of homogeneity within the groups, including homogeneity by ethnicity, gender and if possible, age. The principles guiding these decisions are that the more similar the experiences among group members, the greater sense of community built between members, collective self-esteem, and greater cohesion leading to better outcomes for each individual. According to Yalom (2005), groups are ideally homogenous for earlier work and heterogeneous, mixed groups may be best for an advanced group setting.

In many cultures, it is taboo for women and men to discuss together many of the social, political, and economic topics that could be content for a support group. Both genders may feel uncomfortable opening up and sharing issues that may prove beneficial and healing when discussed separately. Additionally, women and men may also differ in their level of interest in the topics discussed. For women, themes such as care for family, particularly during war, relationships, and parenting issues commonly occur (Kira et al., 2011). For men, these topics seem less important making a mixed gender discussion on these issues less effective.

According to the CTTS clubhouse model, mono-ethnic groups are also important in creating ethnic-specific expression, greater ethnic identification, and collective selfesteem. These groups seem more effective and practical, as mono-ethnic groups have 
shared experiences, language and culture. Age may also be an important factor in separation of groups; however, gender and ethnicity seem to be most important. Nevertheless, because the more similar the experience among group members the better, a 65 year old Iraqi male refugee may have different needs than a 17 year old Iraqi male refugee. At JFCS all of the groups are mono-ethnic while only some of the groups are mono-gender.

Paraprofessional community members facilitate and lead these groups following the model, training and handbook created by JFCS staff. By using leaders within the refugee community JFCS builds on the natural supports already existing within the community. Using a similar argument used as homogeneity of group members, JFCS feels that community members are able to relate and build collective self-esteem better than mental health professionals outside of the community again, due to shared experience, language, and culture. Training and challenges of peer facilitators are discussed in detail later.

\section{Refugee Characteristics}

The characteristics of refugees both before and after their displacement can be predictors of mental health. Female refugees tend to have worse mental health outcomes than male refugees (Porter \& Haslam, 2005; Ringold, Burke, \& Glass, 2005). Older individuals have a more difficult experience with the resettlement process while children and adolescents are less affected by the stresses of displacement (Porter \& Haslam, 2005; Ringold et al., 2005). Higher levels of education and socioeconomic status were also found to be predictors of poorer mental health outcomes (Porter \& Haslam, 2005; Ringold et al., 2005). Once refugees arrive, they can encounter unstable living environments and a lack of economic opportunity, which can further place them at risk for poor mental health outcomes (Cole \& Blythe, 2010). Soon after arrival, children and youth face a unique complication: they often attain language fluency quickly and, as a result are often negotiating the complex role of being an interpreter and culture-broker for parents and elders in their community (Cole \& Blythe, 2010). This displacement of power and cultural expectations can make the acculturation process even more burdensome to families. In the following section, critically important history and data about cultural uniqueness will be discussed to underscore the flexibility of the CTTS model to provide services to an established refugee community and to a newer, growing community in the region.

\section{Iraqi Community}

Administrators at JFCS chose to root their group in the CTTS model because this model has an evidence base for use within the specific communities prevalent in Pittsburgh, PA. In speaking with Bhavini Solanki-Vasan (personal communication, May 12, 2013), the former clinical director of Family Intervention Specialists at CTTS, "Iraqi refugees seem to be much more focused on obtaining jobs and housing rather than addressing any trauma or current stress they have endured." She recommends an adaptation of the original model with the inclusion of a solution-focused approach (based on solution-focused therapy) for Iraqi refugees. 
Solution-focused therapy involves setting clear, specific, and attainable goals and working in small increments to achieve these goals (Malan, Heath, Bacal, \& Balfour, 1975). This type of therapy is used at the Family Center located in Milwaukee with documented success with refugees as well as with other abuse and trauma victims. This strengths-based approach is clearly utilized in work with all clients at JFCS and is incorporative of creating self-sufficient goal setting capability. Peer educators focus on long term goals for clients and utilize group work to share strategies to successfully engage clients in the Pittsburgh services, communities or work forces that will improve life circumstances.

Because of the conservative nature of Iraqi culture, homogeneity of groups by gender is extremely important to the success of the group. Sensitive issues are bound to come up and clients will be more apt to speak openly about these if there is a single gender group. Many individuals who flee their home countries because of changing geo-political factors that result in some aspect of their identity (e.g., being a member of a minority religious sect) putting them at risk of peril often have family still living in their home country (Rosseau, Mekki-Berrada, \& Moreau, 2001; Simich, Hamilton, \& Baya, 2006; Turner, Bowie, Dunn, Shapo, \& Yule, 2003).

A study done with Iraqi Mandaneans, a small pre-Christian sect, prior to the war in 2003 demonstrated high rates of PTSD (29\%) and/or prolonged mental health disability (54\%) in this minority refugee population (Steel, Silove, Brooks, Momartin, Alzuhairi, \& Susljik, 2006). Furthermore, research has found that Iraqi refugees who still have family in Iraq are more likely to experience an increased mental health disability in addition to PTSD and depression (Nickerson, Bryant, Steel, Silove, \& Brooks, 2010). Observations done over the past three years of groups in the Iraqi community of JFCS underscore these findings in that support group members speak about trauma related to their experience in Iraq and/or their experience of resettlement in the USA (JFCS, 2016a). The clinical observer for the Iraqi peer support group additionally observed participants developing friendships and community relationships, increasing knowledge about resources in the community, and venting frustrations/identifying solutions with issues regarding their resettlement (JFCS, 2017a).

The group has provided an opportunity for education and networking opportunities for the refugees. Members report that it has been cathartic just to speak about these issues as it alleviates feelings of isolation. Some of the issues the group is currently grappling with include intergenerational conflicts, deaths of family members in Iraq, experience of discrimination from employers and the recognition/conferral of degrees and titles from Iraq in the US (JFCS, 2016b). The Iraqi group maintains cultural traditions, such as the sharing of fruit, tea and pastries at their meetings; group leaders are given a budget to provide snacks or items to facilitate group cohesion (JFCS, 2016a). The three tenets of the CTTS model are followed while tailoring the group approach to the Iraqi population and the unique challenges they face in the Pittsburgh region. 


\section{Bhutanese Community}

The CTTS clubhouse model has provided group therapy to the Bhutanese, ethnic Nepali (persecuted and forced to flee Bhutan over 20 years ago) community in the past where they incorporated a community representative to lead their groups. A primary goal for the Bhutanese group was to develop a social organization for the Bhutanese community, which in turn would facilitate community healing. Developing social networks can be critical in creating support within the community through mutual sharing of experiences, collective problem solving, and the reduction of feelings of isolation (Miller, 1999).

Currently, the Bhutanese community has a good infrastructure for connecting with its community members. Through the use of the Bhutanese Community Association of Pittsburgh (2016) established in 2012, information is distributed through their weekly community bulletins. These bulletins are done through online video, which makes the information easier to obtain for many Bhutanese due to the high rates of illiteracy within their population.

Sessions have an emphasis on the emotional exploration aspect of the CTTS model as research suggests that the Bhutanese will greatly benefit from exploration through discussion and shared stories. Seminal work done over nearly twenty years underscores the central use of "folk" stories as a way to observe social worlds and to understand the female sense of self in Nepalese (specifically southeastern Tarai culture) (Davis, 2014). Storytelling allows the group members to engage with each other in a manner that allows for collective healing. CTTS uses basic stress coping techniques that could be employed in this model. Such techniques included the use of laughter and humor where group members were encouraged to share humorous events relating to their present situation. The goal was to help normalize issues, deal with stress, and allow for the group members to engage in healthy laughter.

Other group activities used within the Bhutanese community are culturally grounded. These include yoga and meditation, which provide a spiritual approach to the group meetings. The groups being run by and for the Bhutanese community use yoga, breathing techniques, mind/body techniques, music, storytelling, citizenship, active participation from group members and discussions of resources and cultural differences (JFCS, 2016c). Groups ranging in size from 15-40 typically meet early in the day on Saturday. The group often starts with some light physical exercise to get everyone up, moving, and feeling connected to the group (JFCS, 2016d). Next, group members are educated about important issues relevant to their resettlement. This could include the issues of underemployment or unemployment, use of public transportation, understanding different aspects of the public schools and their current emotional status (JFCS, 2016c). Groups always include time for open discussion (topics can include gender roles, cultural beliefs, holidays, school practices) and this can sometimes include a compare/contrast session of how things were in the refugee camps or in their native Bhutan. The time in the camps was very hard, and for some, may result in a diagnosis of PTSD (JFCS, 2015). There is a lot to process in terms of the social, economic and political differences between cultures; the group lends itself naturally to be the host of such conversations. 


\section{Program Evaluation Methods}

\section{Participants}

Participants were adults that participated in a peer support group sponsored by JFCS between August 2016 and August 2017. Two hundred-twenty unique participants participated in at least one group and completed pre-group and/or post-group assessments. Post-group assessments were not completed by a large number of subjects. Additionally, some individuals participated in multiple groups $(n=42)$. This analysis focuses on the 79 unique individuals who completed both pre- and post-group assessment. When a participant completed multiple sessions, data from the earliest session with both pre- and post-group assessments was included. Note: When considering only first-time group participation, pre- and post-group data was available for 45 participants. The results obtained from that sample were qualitatively similar to those presented below, but not all results reached statistical significance due to reduced power. The majority of participants were Bhutanese (ethnic Nepali) (Bhutanese: $n=62$; Congolese: $n=4$; Iraqi: $n=10$; Korean: $\mathrm{n}=3$; Latina; $\mathrm{n}=2$ ). These sample sizes did not allow statistical comparison between groups.

\section{Design}

Training peer educators presents various challenges for those supervising the group. The model utilized by JFCS stresses the importance of using lay leaders, from the communities they intend to peer educate, as they will be able to create a better dynamic within the group rather than using a professional social worker and interpreter. The layout of the 8-week sessions is described in the aforementioned literature review section. During the course of the sessions a clinical observer with a degree in social work sits in on one meeting (approximately 3 hours) for each group cycle. This individual does not have an interpreter and is there to observe group dynamics and group process; the individual debriefs with the group leader at the end of the session to ensure all content discussed is documented. Yalom (2005) suggests that one supervisory hour per group session is the optimal ratio for leaders-in-training. However, this ratio is a guideline for mental health professionals and can be adjusted accordingly for peer leaders.

\section{Measures}

The effectiveness of the support group was measured using an agency-specific pre/post survey that focused on the group goals. Surveys were translated into the languages of the communities served. When clients were not literate, the surveys were intervieweradministered using interpretative services. The questions focused on one's ability to utilize or obtain public transportation, employment services, health services, school, support networks, employment, food, bill payment, and read mail. Group members are then specifically asked about feelings of hopelessness, size of their support network, group and leader satisfaction levels, likelihood of referring others to the group, and need for additional services or referrals. Members are offered space on the pre and post surveys to write in additional comments as necessary. JFCS collects data on whether the survey was read to the member, or completed by the member independently. 
To ensure that accurate feedback is obtained, only individuals who have attended at least four of eight group meetings complete the post-survey. Work, health issues, etc. can affect attendance any given week. JFCS has worked hard to limit the impact of childcare obligations and barriers to transportation by providing bus passes and/or group leaders assist in providing transportation to the groups and baby-sitting. Locations of the groups are carefully determined based on where the participants live.

\section{Results: Paired Samples Analysis}

\section{Analyses}

McNemar's tests were used to compare the responses between pre- and postassessments for questions 1 and 2/3, i.e., Are participants' responses consistent or do they change between the pre-assessment and post-assessment? (Note: binomial exact tests were used if cell counts were too low to use McNemar's test). Questions 4, 5, 6 were scored from $0-2$ based on a 3 level Likert scale and were examined using non-parametric Wilcoxon signed rank tests.

Due to modifications to the survey instrument and missing data, some items do not have data from all participants. Participants who chose "Does not apply" were treated as missing, as this was not an option on some survey versions. All analyses were completed using SPSS v. 25.

Expectations vs. Outcomes. The majority of participants expected group participation to help them with all four items (making friends, getting information, becoming more independent, feeling better about life in America) and for most participants, these expectations were met (see Table 2). However, there was a significant difference in responses for items "Getting information" and "Feeling better about life in America," indicating that not all participants' expectations were met for these two items (all $p s<0.05$ ).

Table 2. Participants' Expectations of How Group Will Benefit Them vs. Reported Benefit at Post-Assessment $(n=78-79)$

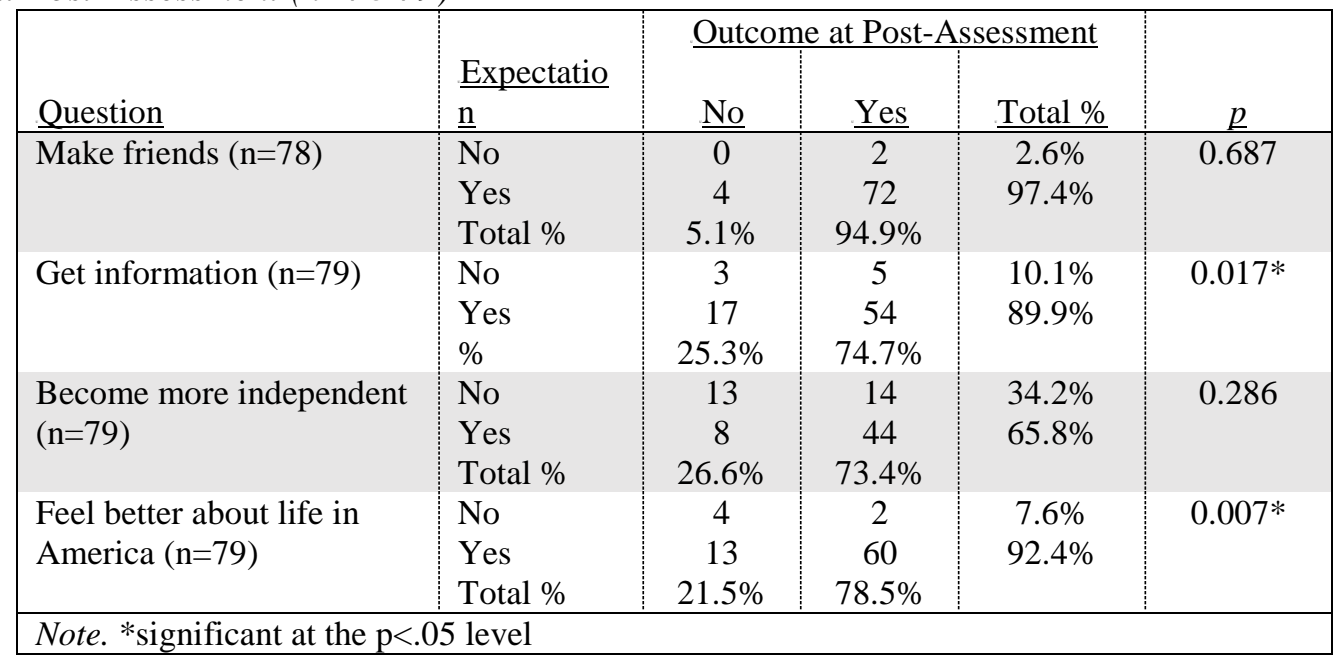


Ability to Access Services. For most items, participants were more likely to report ability to access at completion of the group. This change was significant for accessing transportation, health care, and ethnic community supports (all binomial exact tests, all $p s<0.001$ ). For example, 10 participants reported not being able to access health care before the group, but were able to do so at the end of the group, while only one participant reported change in the opposite direction. (See Table 3 and Figure 1 below). There was not a significant change for some items, e.g., accessing school and jobs. This may be due to changes in whether the person was in school or employed, which was not assessed.

Table 3. Participants' Ability to Access Services ( $n=40-78)$

\begin{tabular}{|c|c|c|c|c|c|}
\hline \multirow[b]{2}{*}{ Question } & \multirow[b]{2}{*}{ Pre-group } & \multicolumn{3}{|c|}{ Post-group } & \multirow[b]{2}{*}{$\underline{p}$} \\
\hline & & No & $\underline{\text { Yes }}$ & Total \% & \\
\hline Transportation $(\mathrm{n}=77)$ & $\begin{array}{l}\text { No } \\
\text { Yes } \\
\text { Total \% }\end{array}$ & $\begin{array}{c}2 \\
2 \\
5.2 \%\end{array}$ & $\begin{array}{c}10 \\
63 \\
94.8 \%\end{array}$ & $\begin{array}{l}15.6 \% \\
84.4 \%\end{array}$ & $0.039 *$ \\
\hline Health care $(n=78)$ & $\begin{array}{l}\text { No } \\
\text { Yes } \\
\text { Total \% }\end{array}$ & $\begin{array}{c}2 \\
1 \\
3.8 \%\end{array}$ & $\begin{array}{c}10 \\
65 \\
96.2 \%\end{array}$ & $\begin{array}{l}15.4 \% \\
84.6 \%\end{array}$ & $0.012 *$ \\
\hline Jobs $(n=40)$ & $\begin{array}{l}\text { No } \\
\text { Yes } \\
\text { Total \% }\end{array}$ & $\begin{array}{c}14 \\
6 \\
50.0 \%\end{array}$ & $\begin{array}{c}13 \\
7 \\
50.0 \%\end{array}$ & $\begin{array}{l}67.5 \% \\
32.5 \%\end{array}$ & 0.167 \\
\hline School $(n=60)$ & $\begin{array}{l}\text { No } \\
\text { Yes } \\
\text { Total \% }\end{array}$ & $\begin{array}{c}3 \\
10 \\
21.7 \%\end{array}$ & $\begin{array}{c}11 \\
36 \\
78.3 \%\end{array}$ & $\begin{array}{l}23.3 \% \\
76.7 \%\end{array}$ & 1.000 \\
\hline $\begin{array}{l}\text { Ethnic community supports } \\
(\mathrm{n}=75)\end{array}$ & $\begin{array}{l}\text { No } \\
\text { Yes } \\
\text { Total \% }\end{array}$ & $\begin{array}{c}2 \\
1 \\
4.0 \%\end{array}$ & $\begin{array}{c}24 \\
48 \\
96.0 \%\end{array}$ & $\begin{array}{l}34.7 \% \\
65.3 \%\end{array}$ & $<0.001^{* *}$ \\
\hline Daily needs (n=74) & $\begin{array}{l}\text { No } \\
\text { Yes } \\
\text { Total \% }\end{array}$ & $\begin{array}{c}3 \\
12 \\
20.3 \%\end{array}$ & $\begin{array}{c}9 \\
50 \\
79.7 \% \\
\end{array}$ & $\begin{array}{l}16.2 \% \\
83.8 \%\end{array}$ & 0.664 \\
\hline
\end{tabular}

Feelings of Hopelessness/Loneliness, Friends, Trust. Results indicated no significant differences between levels of hopelessness/loneliness before and after group participation. However, participants did report an increase in connection and sense of trust with their ethnic community between pre- and post-group assessment $(\mathrm{Z}=-2.78, p=0.005$; See Table 4 and Figure 2). Specifically, 28 participants showed an increase in this measure between the pre-group assessment and post-assessment, while 11 participants showed a decrease. Additionally, there was a trend for participants to report an increase in the number of people in Pittsburgh that they felt comfortable talking to about their problems or worries $(p=0.070)$. 
Figure 1. Participants' ability to access services before/after grp participation ( $n=40-78$ )
Transportation
Health care
Jobs
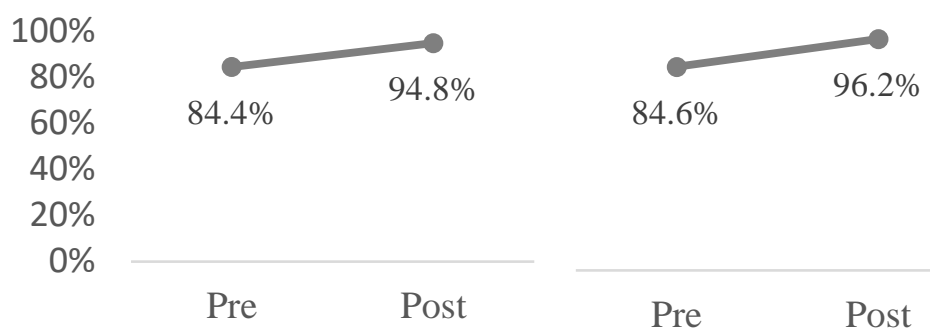

School

Ethnic community

Daily needs

$100 \%$

$80 \%$

$60 \%$

$40 \%$

$20 \%$

$0 \%$

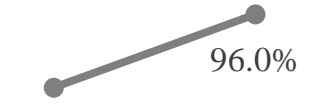

$65.3 \%$

$96.0 \%$
Pre Post

$32.5 \%$

Pre
$50.0 \%$

Post

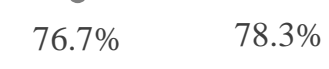

$76.7 \%$

Pre Post

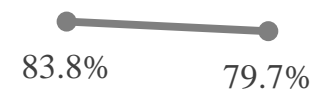

Table 4. Participants' Feelings About Hopeless/Loneliness, People They Can Talk to, Feelings of Trust in Their Community Before and After Participation. $(n=55-75)$

\begin{tabular}{|c|c|c|c|c|c|c|}
\hline \multirow[b]{2}{*}{ Question } & \multirow[b]{2}{*}{ Pre-group } & \multicolumn{4}{|c|}{ Post-group } & \multirow[b]{2}{*}{$\underline{p}$} \\
\hline & & $\frac{\text { Hardly }}{\text { ever }}$ & Sometimes & A lot & $\underline{\underline{\%}}$ & \\
\hline $\begin{array}{l}\text { In the past } 2 \text { months, } \\
\text { how often have you } \\
\text { felt hopeless? ( } n=55)\end{array}$ & $\begin{array}{l}\text { Hardly ever } \\
\text { Sometimes } \\
\text { A lot } \\
\% \\
\end{array}$ & $\begin{array}{c}0 \\
11 \\
4 \\
27.3 \% \\
\end{array}$ & $\begin{array}{c}17 \\
14 \\
1 \\
58.2 \% \\
\end{array}$ & $\begin{array}{c}6 \\
1 \\
1 \\
14.5 \% \\
\end{array}$ & $\begin{array}{l}36.2 \% \\
53.2 \% \\
10.6 \%\end{array}$ & 0.244 \\
\hline $\begin{array}{l}\text { How many people in } \\
\text { Pittsburgh do you feel } \\
\text { comfortable talking to } \\
\text { about your problems } \\
\text { or worries? ( } n=74 \text { ) }\end{array}$ & $\begin{array}{l}\underline{\text { Pre-group }} \\
\text { None } \\
1-2 \\
3 \text { or more } \\
\%\end{array}$ & $\begin{array}{c}\frac{\text { None }}{0} \\
2 \\
0 \\
2.7 \% \\
\end{array}$ & $\begin{array}{c}\frac{1-2}{0} \\
14 \\
12 \\
35.1 \% \\
\end{array}$ & $\begin{array}{c}\frac{3+}{2} \\
22 \\
22 \\
62.2 \%\end{array}$ & $\begin{array}{c}\frac{\%}{0.0 \%} \\
57.1 \% \\
42.9 \%\end{array}$ & $\begin{array}{c}\mathrm{p} \\
0.070\end{array}$ \\
\hline $\begin{array}{l}\text { How much do you feel } \\
\text { a connection and sense } \\
\text { of trust with your } \\
\text { ethnic community? } \\
(\mathrm{n}=75)\end{array}$ & $\begin{array}{l}\text { Pre-group } \\
\text { None } \\
\text { Some } \\
\text { A lot } \\
\%\end{array}$ & $\begin{array}{c}\text { None } \\
0 \\
0 \\
0 \\
0.0 \% \\
\end{array}$ & $\begin{array}{c}\text { Some } \\
0 \\
19 \\
11 \\
40.0 \% \\
\end{array}$ & $\begin{array}{c}\text { A lot } \\
1 \\
27 \\
17 \\
60.0 \% \\
\end{array}$ & $\begin{array}{c}\frac{\%}{0.0 \%} \\
63.3 \% \\
36.7 \%\end{array}$ & $\underset{0.005^{*}}{\mathrm{p}}$ \\
\hline
\end{tabular}


Figure 2. Comparison of "How Much Do You Feel a Connection and Sense of Trust with Your Ethnic Community?” From Pre-Group to Post-Group Assessment

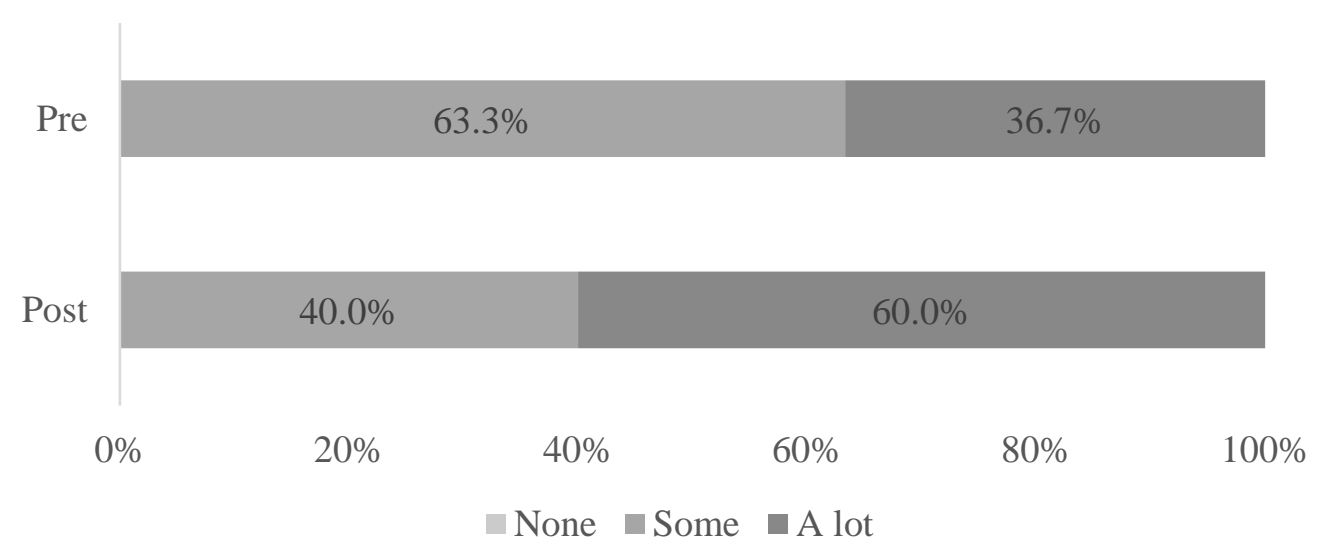

\section{Discussion}

Results indicate that the participants felt significantly more independent and more connected with members of their ethnic community after participation in these groups. This indicates that the groups have been successful in two critical ways that help in the assimilation and acculturation of refugee populations. In general, participants showed an increased ability to access health care, job resources, transportation, school, and their own ethnic community. One surprising finding was that participants' expectations were not met for "Getting information" and "Feeling better about life in America." Possible explanations for this may include the simultaneous ending of case management services, creating a gap in services for those who had not yet fully engaged in services like transportation, food/meals, health care, and employment services. Perhaps feeling more connected to your ethnic community or acculturation may be indicative of the complimentary issue of assimilation to American culture. Many of the individuals who have resettled from Bhutan tend to be older (ages 45+) and research has shown that age is a significant factor in the lengthening the processes of acculturation and assimilation (Cheung, Chudek, \& Heine, 2011).

\section{Limitations}

An important issue to note is that some individuals participated in these groups two, three, and even four times. The groups are designed for disparate states of assimilation/acculturation within groups. Some individuals may feel they have reaped the benefits from the groups with one session (8 weeks) whereas for others repetition of concepts and supports may be necessary for internalization of key concepts and resources. As stated previously, only the earliest record of participation (pre/post) was used for individuals in which, this occurred. Moreover, the agency may want to consider methods of recruitment for the peer groups so that repetition is less of an issue for future groups. Power for this analysis was greatly reduced by the issue of repetition, and the sample size shrunk from 79 to 45 . Even more of an impact was the lack of data from the post surveys. 


\section{Future Directions}

Organizations around the globe are continuing to develop and test programs for refugees and their families (Ostrander, Melville, \& Berthold, 2017). Social work interventions with refugee populations are well equipped to focus on the strengths perspective by incorporating empowerment workshops into curricula for assimilation and acculturation (Carlson, Cacciatore, \& Klimek, 2012). Empowerment workshops are another creative treatment being used to heal refugees. Free to Grow (FTG), an organization using a holistic approach to well-being has been employed by organizations such as UNICEF and MultiChoice Africa to provide workshops for refugees and survivors across the globe (Jaranson \& Quiroga, 2011). The workshops focus on life skills, interpersonal growth, self-esteem, and the "ownership" of personal growth and development. FTG workshops include 4 sessions spanning 4 days. In the context of family work, the Cultural Context Model aims to make clients aware of the context of power and privilege in their newly adapted culture (environment) and provides them with a familybased intervention that simultaneously seeks to ensure social justice (McDowell, Libal, \& Brown, 2012).

Group work is particularly effective with small groups of individuals who have had similar experiences (i.e., siblings, peer groups, or others from refugee backgrounds) to demonstrate shared feelings and show those who feel alienated that they are not alone (McMahon, 2009, p. 75-76). Working with refugee clients from similar backgrounds in a group setting also promotes community-building through cultural education and preservation (A.R.T., 2017). Many refugee populations demonstrate this, such as at the Za'atari refugee camp in Jordan where community artwork represents a variety of cultural themes and issues. Group work allows clients to develop social skills, decreases feelings of isolation through peer support, and increases self-awareness (Coholic, 2010). Research has shown that children and adults alike are able to bond with others, both locally and internationally, through their creativity, empowering them to overcome obstacles and increasing their self-esteem (Ely, Koury, Bennett, Hartinger, Green, \& Nochajski, 2017).

The peer support group model provides clients with the social network and grounding in community resources necessary for them to feel a sense of mastery in their new environment. However, it is also limited in scope because the leaders do not have a specific therapeutic mental health and/or clinically therapeutic focus in the work that is being done. Future direction may include utilizing a social worker beyond the training of the peer leaders and instead engaging leaders in a more in-depth social work educational experience; including, but not limited to, taking select social work courses at local community colleges with a focus on ethics, interviewing and engagement skill building.

Currently JFCS offers additional supportive services to refugees including the Immigrant Services \& Connections (ISAC) program that connects refugees to existing services in the community. Future directions for work with this population may include additional training for peer leaders in specific trauma-informed care and group mental health strategies and may also include augmenting sessions with a clinician who can provide mental health screenings and referral to individual or family counseling resources. 


\section{References}

Art for Refugees in Transition [A.R.T.]. (2017). About A.R.T. Retrieved from http://www.artforrefugees.org/about.html.

Bass, J. K., Annan, J., McIvor Murray, S., Kaysen, D., Griffiths, S., Cetinoglu, T., \& ... Bolton, P. A. (2013). Controlled trial of psychotherapy for Congolese survivors of sexual violence. New England Journal of Medicine, 368(23), 2182-2191. doi: https://doi.org/10.1056/NEJMoa1211853

Broadhead, R., Heckathorn, D., Altice, P., van Hulsta Y., Carbonec, M., Friedland, G. H., O’Connor, P. G., \& Selwynd, P. A. (2002). Increasing drug users' adherence to HIV treatment: Results of a peer-driven intervention feasibility study. Social Science and Medicine, 55(2), 235-246. doi: https://doi.org/10.1016/S0277-9536(01)00167-8.

Bhutanese Community Association of Pittsburgh. (2016). Home. Retrieved from http://www.bcap.us.

Carlson, B., Cacciatore, J., \& Klimek, B. (2012). A risk and resilience perspective on unaccompanied refugee minors. Social Work, 57(3), 259-269. doi: https://doi.org/10.1093/sw/sws003

Cheung, B., Chudek, M., \& Heine, S. (2011). Evidence for a sensitive period for acculturation: Younger immigrants report acculturating at a faster rate. Psychological Science, 22(2), 147-152. doi: https://doi.org/10.1177/0956797610394661

Coholic, D. (2010). Arts activities for children and young people in need: Helping children to develop mindfulness, spiritual awareness and self-esteem. London and Philadelphia, PA: Jessica Kingsley Publishers.

Cole, A., \& Blythe, B. (2010). Mentoring as an alternative to therapy for immigrant and refugee youth. Revista de Asistenta Sociala, 9, 149-156.

Congress, E. P., \& Chang-Muy, F. (2015). Social work with immigrants and refugees: Legal issues, clinical skills, and advocacy (2nd ed.). New York, NY: Springer.

Davis, C. (2014). Maithil women's tales: Storytelling on the Nepal-India border. Urbana: University of Illinois.

Drozdek, B., \& Bolwerk, N. (2010). Evaluation of group therapy with traumatized asylum seekers and refugees- the Den Bosch model. Traumatology, 16(4), 117-127. doi: https://doi.org/10.1177/1534765610388298.

Ely, G., Koury, S., Bennett, K., Hartinger, C., Green, S \& Nochajski, T. (2017). “I feel like I am finding peace": Exploring the use of a combined art therapy and adapted seeking safety program with refugee support groups. Advances in Social Work, 18, 103-115. doi: https://doi.org/10.18060/21130.

Fischhoff, A. (1986). Birth to three: A self-help program for new parents. Eugene, OR: Castalina. 
Fischman, Y., \& Ross, J. (1990). Group treatment of exiled survivors of torture. American Journal of Orthopsychiatry, 60, 135-142. doi: https://doi.org/10.1037/h0079191

Geltman, P. L., Augustyn, M., Barnett, E. D., Klass, P.E., \& Groves, B. M. (2000). War trauma experience and behavioral screening of Bosnian refugee children resettled in Massachusetts. Journal of Developmental \& Behavioral Pediatrics, 21, 255-260. doi: https://doi.org/10.1097/00004703-200008000-00001.

Im, H., \& Rosenberg, R. (2016). Building social capital through a peer-led community health workshop: A pilot with the Bhutanese refugee community. Journal of Community Health, 41(3), 509-517. doi: https://doi.org/10.1007/s10900-015-0124-z.

Jaranson, J. M., \& Quiroga, J. (2011). Evaluating the services of torture rehabilitation programmes: History and recommendations. Torture: Quarterly Journal on Rehabilitation of Torture Victims and Prevention of Torture, 21(2), 98-140.

Karcher, M., Kuperminc, G., Portwood, S., Sipe, C., \& Taylor, A. (2006). Mentoring programs: A framework to inform program development, research, and evaluation. Journal of Community Psychology, 34, 709-725. doi: https://doi.org/10.1002/jcop.20125

Kaslow, F. (2014). Intervening with immigrant families: An integrative systems perspective. Journal of Family Psychotherapy, 25, 177-191. doi: https://doi.org/10.1080/08975353.2014.910031.

Kim, S. (2013). Re-discovering voice: Korean immigrant women in-group music therapy. The Arts in Psychotherapy, 40, 428-435. doi: https://doi.org/10.1016/j.aip.2013.05.005.

Kira, I., Ahmed, A., Mahmoud, M., \& Wassim F. (2010). Group therapy model for refugee and torture survivors, Torture, 20(2), 108-113.

Kira, I., Ahmed, A., Wasim, F., Mahmoud, V., Colrain, J., \& Rai, D. (2011). Group therapy for refugees and torture survivors: Treatment model innovations. International Journal of Group Psychotherapy, 62(1), 69-88. doi: https://doi.org/10.1521/ijgp.2012.62.1.69.

Lubin, H., Loris, M., Burt, J., \& Johnson, D. (1998). Efficacy of psychoeducational group therapy in reducing symptoms of posttraumatic stress disorder among multiply traumatized women. American Journal of Psychiatry, 155, 1172-1177. doi: https://doi.org/10.1176/ajp.155.9.1172.

Malan, D., Heath, E., Bacal, H., \& Balfour, F. (1975). Psychodynamic changes in untreated neurotic patients: II. Apparently genuine improvements. Archives of General Psychiatry, 32, 110-126. doi: https://doi.org/10.1001/archpsyc.1975.01760190112013

McDowell, T., Libal, K., \& Brown, A. L. (2012). Human rights in the practice of family therapy: Domestic violence, a case in point. Journal of Feminist Family Therapy, 24(1), 1-23. doi: https://doi.org/10.1080/08952833.2012.629129. 
McMahon, L. (2009). The handbook of play therapy and therapeutic play. New York, NY: Routledge.

MENTOR: The National Mentoring Partnership. (2009). Mentoring immigrant and refugee youth: A toolkit for program coordinators. Retrieved on June 8, 2010, from https://www.mentoring.org/new-site/wpcontent/uploads/2015/09/Mentoring Immigrant and Refugee YouthA_Toolkit_for_Program_Coordinators.pdf

Miller, K. (1999). Rethinking a familiar model: Psychotherapy and the mental health of refugees. Journal of Contemporary Psychiatry, 29, 283-306.

Nickerson, A., Bryant, R., Steel, Z., Silove, D., \& Brooks, R., (2010). The impact of fear for family on mental health in a resettled Iraqi refugee community. Journal of Psychiatric Research, 44, 229-235. doi: https://doi.org/10.1016/j.jpsychires.2009.08.006.

Obradovic, J., Tirado-Strayer, N., \& Leu, J. (2013). The importance of family and friend relationships for the mental health of Asian immigrant young adults and their nonimmigrant peers. Research in Human Development, 10(2), 163-183. doi: https://doi.org/10.1080/15427609.2013.786559

Ostrander, J., Melville, A., \& Berthold, S. M. (2017). Working with refugees in the US: Trauma-informed and structurally competent social work approaches. Advances in Social Work, 18, 66-79. doi: https://doi.org/10.18060/21282.

Porter, M., \& Haslam, N. (2005). Predisplacement and post displacement factors associated with mental health of refugees and internally displaced persons: A metaanalysis. The Journal of the American Medical Association, 294, 602-612. doi: https://doi.org/10.1001/jama.294.5.602

Ringold, S., Burke, A., \& Glass, R. M. (2005). Refugee mental health. The Journal of the American Medical Association, 294, 646. doi: https://doi.org/10.1001/jama.294.5.646

Rosseau C., Mekki-Berrada A., \& Moreau S. (2001). Trauma and extended separation from family among Latin American and African refugees in Montreal. Psychiatry: Interpersonal and Biological Processes, 64, 40-59. doi: https://doi.org/10.1521/psyc.64.1.40.18238

Schweitzer, R. D., Brough, M., Vromans, L., \& Asic-Kobe, M. (2011). Mental health of newly arrived Burmese refugees in Australia: Contributions of pre-migration and post-migration experience. Australian and New Zealand Journal of Psychiatry, 45, 299-307. doi: https://doi.org/10.3109/00048674.2010.543412.

Shannon, P. J., Vinson, G. A., Wieling, E., Cook, T., \& Letts, J. (2015). Torture, war trauma, and mental health symptoms of newly arrived Karen refugees. Journal of Loss and Trauma, 20(6), 577-590. doi: https://doi.org/10.1080/15325024.2014.965971. 
Shannon, P. J., Wieling, E., Simmelink-McCleary, J., \& Becher, E. (2015). Beyond Stigma: Barriers to Discussing Mental Health in Refugee Populations. Journal of Loss \& Trauma, 20(3), 281-296. doi: https://doi.org/10.1080/15325024.2014.934629.

Simich L., Hamilton, H., \& Baya B. (2006). Mental distress, economic hardship and expectations of life in Canada among Sudanese newcomers. Transcultural Psychiatry, 43, 418-444. doi: https://doi.org/10.1177/1363461506066985

Steel, Z., Silove, D., Brooks, R., Momartin, S., Alzuhairi, B., \& Susljik, I. (2006). Impact of immigration detention and temporary protection on the mental health of refugees. British Journal of Psychiatry, 188, 58-64. doi: https://doi.org/10.1192/bjp.bp.104.007864.

Stewart, M., Simich, L., Shizha, E., Makumbe, K., \& Makwarimba, E. (2012). Supporting African refugees in Canada: Insights from a support intervention. Health \& Social Care in the Community, 20(5), 516-527. doi: https://doi.org/10.1111/j.1365-2524.2012.01069.x

Strand, V., Popescu, M., Way, I., \& Jones, A. (2017). Building field agencies’ capacity to prepare staff and social work students for evidence-based trauma treatments. Families in Society, 98(1), 45-56. doi: https://doi.org/10.1606/1044-3894.2017.8

Thomas, L., Clarke, T., \& Kroliczak, A. (2008). Implementation of peer support demonstration project for HIV+ Caribbean immigrants: A descriptive paper. Journal of Immigrant \& Refugee Studies, 6, 526-544. doi: https://doi.org/10.1080/15362940802480407

Turner, S., Bowie, C., Dunn, G., Shapo, L., \& Yule, W. (2003). Mental health of Kosovan Albanian refugees in the UK. British Journal of Psychiatry, 182, 444-448. doi: https://doi.org/10.1192/bjp.182.5.444.

United Nations High Commissioner for Refugees. (2010). Convention and protocol relating to the status of refugees. Retrieved from http://www.unhcr.org/protect/PROTECTION/3b66c2aa10.pdf

Watters, C. (2001). Emerging paradigms in the field of mental health care of refugees. Social Science and Medicine, 52, 1709-1718. doi: https://doi.org/10.1016/S02779536(00)00284-7.

Webel, A., Okonsky, J., Trompeta, J., \& Holzemer, W. (2010). A systematic review of the effectiveness of peer-based interventions on health-related behaviors in adults. American Journal of Public Health, 100(2), 247-253. doi: https://doi.org/10.2105/AJPH.2008.149419.

Yalom, I. (2005). The theory and practice of group psychotherapy. New York City, NY: Basic Books.

Author note: Address correspondence to: Azadeh Masalehdan Block, MSW, $\mathrm{PhD}$ Assistant Professor, Department of Social Work, California University of PA, Box 90, California, PA 15419. Email: block@calu.edu 